\title{
Linguistic Disadvantage and Authorial Identity in Research Articles Written by Native English and Thai Writers in International Publication
}

\author{
Darunee Yotimart (Corresponding author) \\ School of Languages, Civilisation \& Philosophy, UUM College of Arts and Sciences, Universiti Utara Malaysia, Malaysia \\ E-mail daruneeyo@hotmail.com \\ Noor Hashima Abd. Aziz \\ Department of Language Studies, School of Languages, Civilisation \& Philosophy, UUM College of Arts \& Sciences, Universiti Utara Malaysia, \\ Malaysia \\ E-mailnoor934@uum.edu.my
}

\author{
Received: 14-03-2017 \\ Accepted: 07-05-2017 \\ Advance Access Published: July 2017 \\ Published: 01-09-2017 \\ doi:10.7575/aiac.ijalel.v.6n.5p.206 \\ URL: http://dx.doi.org/10.7575/aiac.ijalel.v.6n.5p.206
}

\begin{abstract}
Research have reported that one of the challenges faced by non-native English writers to have their research articles (RAs) accepted by English-medium journals is to fulfill the journals' expectations in terms of linguistic aspect. In addition, non-native English writers seem to be having the problem in expressing their authorial identity which is needed to build one's academic arguments. Therefore, this research was conducted to 1) explore whether linguistic disadvantage exists among native English writers or Thai writers in international publication, and 2) discover how the native English and Thai writers assert their identities through different rhetorical purposes of RAs. Eight university lecturers in Applied Linguistics (AL) from a few universities in Thailand were interviewed to understand their views on the issues of writing for scholarly publication in the English language. The findings revealed two salient emerging themes: (1) the role of linguistic disadvantage and (2) variation in authorial identity between native English and Thai writers. The study has found that linguistic disadvantage exists among the Thai writers. The native English writers expressed their authorial identity overtly but the Thai writers deferred their authorial identity. It is suggested that teachers in Thailand emphasize more on the knowledge of linguistic aspect required in international publication and the effective use of linguistic realization of authorial identity in academic writing.
\end{abstract}

Keywords: linguistic disadvantage, authorial identity, research articles, rhetorical purpose, native English writers, Thai writers, international publication

\section{Introduction}

English is used in every sphere of professional and scholarly communication, particularly in higher education worldwide. It has become one of the main tools for disseminating advanced knowledge through research articles (RAs) from studies conducted by scholars worldwide (Khamkhien, 2014). The increasing dominance of English in the academic world has markedly contributed to the increasing number of scholars whose first language is not English, striving to build international academic recognition through publishing in English-medium journals (Hyland, 2012). This phenomenon has triggered conflicting opinions among scholars whether non-native English writers face more challenges in the publication of academic work compared to their native English counterparts. Swales (2004) argues that native and non-native English writers are equal in the reviewing process of their papers in international journals. He ascribes content-based aspect (e.g., lack of clarity in presenting results) as the main rejection criteria rather than linguistic ones. In the same vein, Hyland (2016) argues that there is little convincing evidence that a linguistic disadvantage exists. In contrast, Politzer-Ahles, Holliday, Girolamo, Spychalska, \& Berkson (2016), in response to Hyland's argument, argue that linguistic disadvantage does exist and has an impact in academia. Likewise, Curry and Lillis (2010) found that the lack of English competence among non-native English writers could fail them to meet the reviewers and editors' expectations. In fact, some researchers (Al Fadda, 2012; Flowerdew, 1999; Okamura, 2006) identified problems faced by non-native English writers to get their RAs published in international journal, for example, textual organization, longer time to write in English, lack of vocabulary, the difficulties in the use of hedging expression. However, studies specifically on whether linguistic disadvantage exists among the native English or Thai writers are still lacking. Therefore, this study hopes to provide insight into linguistic aspects which might impede the writers to get published in international journals.

Whether adhering to one view or the other, what these conflicting opinions show is that the use of English by nonnative writers in international publication differs to some extent from the native English writers' standards. Non-native 
writers are reported to represent themselves differently from the native writers in terms of discoursal practices in academic writing (Hyland, 2002a, 2002b; Ivanic and Camps, 2001; Lin, 2013; McCrostie, 2008; Petch-Tyson, 1998). This line of enquiry has led to a critical review of culture-specific practices in academic genre, and has prompted writers to take the existence of different scholarly traditions and culture-specific rhetorical preferences into consideration to help achieve credibility, highlight research findings and finally gain the acceptance of their discourse communities.

In recent years, scholars have agreed that interaction plays a crucial role in negotiating the relationship between writers' arguments and their academic discourse communities, leading writers to create authorial identity (Hyland, 2001). Other terms for authorial identity are author's authority and visibility and authorial voice (Flowerdew \& Wang, 2015; Hyland, $2002 \mathrm{~b}$ ). The use of authorial identity to limit claims, enhance possibility and promote personal credibility can have a positive effect on building one's academic arguments. Therefore, knowledge about the strategic use of authorial identity is of great importance to journal article writers (Hyland, 2005). However, the lack of voice or incapability of expressing own voice has been found to be a major problem among non-native writers (Cadman, 1997; Fox, 1994; Prince, 2000), especially among East Asian writers (Hyland, 2002a, 2002b; Swale, 1990), such as Thai writers who seem to defer to authority in their writing (Flowerdew, 2001).

Based on interviews with international editors, Flowerdew (2001) found that the lack of authorial identity or the lack of voice or an authority in the expression of authors as part of their discourse community to be a major problem in RAs written by Thai writers. Some journal editors interviewed in the study expressed that the lack of authorial identity might be a characteristic of novice writers in general, while others considered it as a possible trait of East Asian writers, such as Thai authors. From the interviews, the lack of authorial voice among Thai academic writers was ascribed to Thai culture or trait which values less confrontation when interacting with others. However, this finding was based on only outsiders' opinion. Therefore, a study which includes insiders' opinion, in this case, Thai editors and experienced Thai academic writers is needed. It is hoped that this study can provide a better understanding on the role of culture or trait which is part of one's discourse community.

To date, numerous studies have found some variations in the use of linguistic realization of authorial identity between native and non-native English writers in cultural contexts such as follows: native English and Chinese writers (Lin, 2013), native English and Japanese writers (McCrostie, 2008), native English and Spanish writers (Pérez-Llantada, 2007), native English and Iranian writers (Kuhi, Tofigh, \& Babaie, 2013), native English and French, Dutch, Swedish writers (Petch-Tyson, 1998). Among cross-cultural studies of authorial identity, the comparison between native English and Thai writers are found to be lacking. Most previous studies relative to this inquiry employed both quantitative (frequency counts of linguistic realization of authorial identity) and qualitative (content analysis) as the main research method. Very few studies used interviews to find out writers' perceptions and motivations on expressing authorial identity in RAs. The interview method has been proven to be valuable for gathering information about the writers' views on their writing practices within an institutional context and on the production and reception histories of their RAs (Perez-Llantada, 2007). To gain insight into this phenomenon, this study therefore seeks to explore whether linguistic disadvantage exists among native English writers or Thai writers in international publication as well as to discover how the native English and Thai writers assert their identity in RAs through rhetorical purposes of RA sections.

\section{Method}

The data for this study were collected through interviews with experienced writers in Applied Linguistics (AL). To carry out the contrastive analysis, eight informants or writers affiliated to different universities in Thailand were interviewed, four are native English and four are Thai writers (see Table 1). Two native informants were editors of international journals in AL and one Thai informant was an editor of international journals in AL. For the sake of consistency, the writers selected for the study were all permanent staff (either senior lecturers or full professors) and had more than 5 years experience of publishing internationally in AL, in order to show that they were familiar with the generic pattern of RAs. The semi-structured interviews were used to help the researcher to prepare questions beforehand. At the same time, the informants could freely express their views in their own terms. The researcher tape-recorded the interviews and later transcribed them verbatim for content analysis.

Table 1. General information about the informants

\begin{tabular}{lcccc}
\hline & $\begin{array}{c}\text { Academic Status in } \\
\text { AL }\end{array}$ & $\begin{array}{c}\text { Experience in } \\
\text { publishing }\end{array}$ & $\begin{array}{c}\text { English } \\
\text { nativeness }\end{array}$ & $\begin{array}{c}\text { An editor of } \\
\text { Journal in AL }\end{array}$ \\
\hline Informant 1 & Assoc. Prof. Dr. & 30 years & NS & $\checkmark$ \\
Informant 2 & Assoc. Prof. Dr. & 30 years & NS & $\checkmark$ \\
Informant 3 & Senior Lecturer Dr. & 10 years & NS & NS \\
Informant 4 & Senior Lecturer Dr. & 6 years & Thai & \\
Informant 5 & Assist. Prof. Dr. & 6 years & Thai & \\
Informant 6 & Assoc. Prof. Dr. & 10 years & Thai & $\checkmark$ \\
Informant 7 & Assist. Prof. Dr. & 8 years & Thai & \\
Informant 8 & Senior Lecturer Dr. & 8 years & & \\
& & & & \\
\hline
\end{tabular}


The thematic analysis (Braun \& Clarke, 2013) was used to analyze the interviews in the current study. The first stage in thematic analysis is doing the coding. The next stage is the theme development. At this stage, the interview transcripts were read and reread to observe substantial broader patterns of meaning (potential themes).

\section{Results}

Having analyzed informants' interview scripts with regards to their assertion of viewpoint or position in RAs, two themes were derived: (1) the role of linguistic disadvantage and (2) variation in authorial identity between native English and Thai writers.

\subsection{The Role of Linguistic Disadvantage}

This theme captured the informants' response in relation to the comments made by the blind reviewers about their RAs. In relation to all the four native English informants, none of them received any comments on language use. During the interviews, they were asked if they felt advantage of being a native speaker writing RAs in English. Even though all of them admitted feeling advantage of being a native speaker, two of them asserted that the main advantage was having exposure to academic research. For example, Informant 1 asserts that "it depends on how your vocabulary is highly pretty much correlate with how much you read. The more you read, the greater vocabulary. It is a general rule... and Thai people don't read". Both native informants (Informants 1 and 2) voice out this point as follows:

Yes, sure (advantaged) but my main advantage is my experiences in research and that is not an issue of being a native speaker. It is much easier for me. The more you read academic writing, the more phrases available to you. It is more about being exposed to academic register... I think that the only major benefit of being a native speaker is being able to access a much larger... vocabulary which allows you to make a more nuanced argument. You can say the exact thing you want to say. You can say the thing to make it sound nice. But it isn't the issue of whether the article is accepted or not. It is nice but there are quite a few of native speakers who write a boring or in vain. (Informant 1 )

Informant 2 further argues that:

Yes, of course I do (advantaged). But I also learn a lot. It is just larger than being a native and you can write very well. It is not true at all. And any universities in the UK where they get students coming in to do a BA or MA, there was what we call miscommunication... It depends. I went to French university. I was often told that my French vocabulary is excessive as I speak French all the time and much more than other languages. The problem with vocabulary here is the Thais did not speak English...exposure to English. (Informant 2)

As for the Thai informants, unlike the native English informants, three Thai informants received comments on their language from reviewers or peer reviewers with respect to their coherence in writing in English. All the Thai informants at times needed to turn to a native English speaker to proofread their RAs submitted to international journal, including Informant 7 who says that "Sometimes I need a native English speaker to proofread my work before submission." Furthermore, Informant 5 said that for her case, she had her co-author who is a native English speaker checked her English language. Then she received comments that her language was not smooth or uneven tone, resulting in lack of fluency. She further points out a strong point in the writing style of a native English writer's RA, compared to a Thai writer:

A native English writer is skillful in employing less number of words to express a certain idea compared to a Thai writer whose English language tends to be redundant...we are influenced by our mother tongue... when I read a Thai writer's English paper, I found language pointless... a native speaker knows how to write to avoid showing a red flag (use the language that avoids a conclusive remark that is likely to get an opposition from the community of experts). I just wonder if they study this skill in school.

Informant 5 mentions that the more we read or are exposed to the academic genre, the larger our vocabulary repertoire that helps us select a proper word or phrase in academic writing. In addition, Informant 6 admits that she can clearly recognize a research article written by a Thai writer because the sentences are influenced by a direct translation from Thai language into English language. She comments that a Thai writer who writes in English is likely to explain things repetitively and long-winded, unlike a native English writer who tends to be more concise. She also mentions about being demotivated in writing RAs in English. However, Informant 8 asserts that he used to think he was at a disadvantaged until he becomes a journal editor. He comments that:

I feel advantaged being a non-native speaker writing a paper because we know the context or real problem of non-native English speaker in using English better than a native speaker does. When we write about the problem in using English among a non-native speaker, a native speaker will be interested in our papers because they want to know the issues in the real context. Even though we are not good at grammar, we can turn to a native English to edit. As a non-native speaker, we have high awareness because when studying, we are taught about a particular pattern of writing. It is the same case as a foreigner who studies Thai language has to learn a lot about the proper use of language and pattern. We use Thai automatically, so we are more likely to lack awareness. This is another disadvantage. Most importantly, I am an editor, I have read many native and nonnative English papers. I certainly say that they are not better than us. If we take a formality or register awareness into consideration, a native speaker is worse than us. They don't aware of formal or informal words which can suggest academic or non-academic level. 
In addition, he mentions that to write a good academic RA, especially on the discussion section, needs experiences of academic exposure, as supported by Informants 1 and 2. Even though Informant 8 feels advantaged of being a nonnative English speaker writing a research article in English, the above excerpt shows that the advantage is merely in the generic awareness of the academic register. As we can see, the disadvantages of being a non-native speaker in terms of language use still outweigh the advantages, especially in terms of linguistic problems (e.g., grammatical mistake). Informants 2 and 7 also express their concerns about grammatical problem as the most problematic issue among their Thai students writing in English.

However, the issue of having more exposure to experts' and academic discourse are important factor that impacts the quality of RAs, compared to whether the writer is a native English speaker or a non-native speaker.

\subsection{Variation in Authorial Identity between Native English and Thai Writers}

This theme captured the informants' use of the linguistic realization of authorial visibility (e.g. self-mentions). The native English informants were comfortable to reveal themselves openly or assert their points of view in their RAs, but the Thai informant avoided expressing themselves overtly due to their concerns about getting negative feedbacks. All the four native English informants asserted that personalization is part of assertion in RA writing. Informant 3 mentions that at present it is permissible for assertion like 'I argue that...' in academia. Summing up, all the native English informants stress that the use of authorial visibility depends on the research paradigm, and must be supported by evidence. It requires some kinds of balance. For example, Informant 1 provides a practical view with regards to how to balance authorial identity as follows:

It depends on the research. It depends on paradigm we working within. It depends on whether I actually become important in the research stage or not. I like this example. I am the interviewer. Being an interviewer means that I am part of the research process, like you are now. So...one aspect of interviewing people is the relationship and etc. And I can argue that I have relationship with my subjects as I work with them for 12 years. That is clearly something that is highly personal but it affects the research. It shows that I have a clear relationship with those subject which there are unlikely to be any issues or less likely to be miscommunication in the interview. If you... two or three years ago there are articles in Applied Linguistics about interviewing. (H) I can't remember. You have to read as he criticized those interview report or research for not giving enough information about interview process. This is clearly that I am part of the research process. When you see ' $\mathrm{I}$ ' in my work, it means that is my argument. It is new and no one else has ever made... If I am saying 'it is argued that..,' I need to give a citation because I imply a general argument in that way. It is my argument which is new. I don't need to hide 'I'... If you don't use 'I' in a personal introspection article, I could be bloody stupid because it is an article with personal introspection... I mean if they cite themselves 20 times and they don't cite anyone else that is when self-mention is a problem; otherwise, self-mention is not a problem.

However, he argues that the use of 'the researcher' quite often sounds very awkward to him because we are trying to distance ourselves which is awkward.

In contrast, interviews with the Thai participants suggest that they are hesitant to employ linguistic realization of authorial identity in their RAs. All the four of them said that they would express themselves comfortably if their assertion does not attack others. Interestingly, all of them have a consensus on not using the first person pronoun 'I,' but preferably 'the author' or 'the researcher' because they hold concerns about the extent of politeness in academic register. They also ascribe this avoidance of explicit self-representation to their preference, which is related to the avoidance of face-threatening. Informant 6 accepts the fact that she lacks confidence in assuring things. In addition, Informant 8 recounts his experience of facing the problem of personal pronoun use that made him decide to refrain from using 'I' explicitly when writing a research article published in Thailand, whereby he was taught that 'I' and 'we' are informal:

When I studied in England, it is different as 'I' or 'we' can prevalently be used to indicate our voice and it shows an author as a part of a research community, not a peripheral part. When I came back to Thailand, I still had a problem which style of writing that should be used. However, I will depend on the editor. If they are a native speaker, I will choose writing style of England and if they are Thai scholars (who adhere to the conventional writing style); otherwise, I could meet a conflict...There was one experienced Thai scholars criticized his work (the informant's friend) not academic because he used personal pronoun 'I'.

Informant 8 also explains why ' $I$ ' is to some extent not preferred in Thai academic context:

This conception of not using 'I' or 'we' is influenced by L1 interference. You can notice that in Thai academic writing, we don't use 'Kapajao' (which means 'I') in writing, but we use 'Nganvijai' (the research) instead. Another reason is what we have been taught from old Thai teachers that we have to maintain objective and impersonal as much as possible in academic writing to make it look formal.

He also mentions that the lack of confidence to use attitudinal markers (e.g. surprising) to assert an author's position resulted from Thai culture which prefers to use 'it is an interesting finding', rather than 'the finding surprises us.' Then, Thai culture is probably a collectivism in which a confrontation is avoided in order to save face. Informant 1 also has the same opinion by assuming that "probably Thais feel they shouldn't say negative thing about other people's works. Maybe a face saving issue." 
For objective Two of the study concerning authorial identity under the rhetorical purposes of each section of RAs, all of the informants did not focus on the Method and Result sections in their discussion because these sections are not problematic in terms of authorial identity expression and have certain format to conform to. Therefore, the researchers of this study will discuss the essential points of the problem of authorial identity in the introduction section and the discussion/conclusion section in RAs.

As for the introduction section, Informant 1 raises the issue about the misconception among academic writers towards the rhetorical purpose of this section, especially the literature review part. He contends that the purpose of literature review is to justify the research topic and research questions. It is not to review the literature. Reviewing literature can help but it is not the purpose. This misconception of writing is found among the novice academic writers, rather than Thai or any non-native writers. He comments that:

People think that the purpose of literature review is to review the literature. That's nonsense. A literature review is not a review of literature. A literature review presents an argument. People think that the purpose of literature review is review literature; they just have paragraphs for review and don't go anywhere. But I don't think that is necessarily Thai but just novice academic writers.

In similar vein, as for the perception among the Thai informants, two of the native English informants (Informants 1 and 2) state that the introduction section is the most difficult to write because they have to provide their own rationales of the study to justify their research topic. Informant 8 discusses about his students' problem in writing this section:

Most Thai writers has a problem with writing the introduction section because they lack knowledge in the research problem. Some of my PhD. students' introduction writings are in vain as they wrote something very superficial and trivial, including a lots of unnecessary background. They are supposed to go right to the point. They should have emphasized on gap filling or weakness by commenting other works, etc. They lack confidence to pinpoint other works' weakness. This kind of introduction has been prevailing in Thai academic community.

As for the discussion/conclusion section, all the Thai informants highlight that this section requires the most expression of authorial identity, compared to the other sections. For example, Informant 2 explains situation as follows:

Wow it (authorial identity) is mainly in the conclusion, but you got to, as in academic writing, is asserting yourself, but in impersonal way. You can't not say 'I' 'I' 'I'. .. Because as you know when 'socio' come with interpersonal aspect of language where you should not come as far as possible assert yourself in such a way that you say 'I absolute believe' or 'this certainly shows' or 'this proves that' you should not write like that because you should hedge. You know the principal of hedging and sometimes you know... you do have to look at the...making a point as what you think. I mean what the conclusions are from this study. Whether to draw from evidence from the text, not making some sort of pronouncement. What I am saying is from the text.

Therefore, a proper hedging is highly important for this section, as supported by Informant 8 who states that "this section requires the intervention of rhetorical language tactics that persuades a reader along with the argument made, for example, a proper use of hedging. Most Thai writers seem to confirm their finding in this section." He further recounts his experience, as an editor, about Thai writers' problem in writing which is too general in expressing authorial identity:

When it comes to the discussion section and limitation of the study, they opt to be neutral or broad in discussing their limitation, for example, 'the study can't be generalized because of the low number of subjects'... They avoid speaking about their weakness because they are afraid that they have to save face by not saying thing negatively. This kind of writing leads to a lack of authority and authorial voice.

Informant 6 has the same opinion. When reviewing RAs written by Thais, she found the Thai writers to be weak at writing the discussion section. She found similar patterns of writing as explained by Informant 8 . But she adds that this problem resulted from the academic teaching in Thailand which does not focus on analytical skill but only on fix form/formula. The critique that Thais tend to focus on form, rather than content was mentioned by Informant 4 who found this trait among the Thai reviewers during the acceptance process in a Thai-based journal.

However, the problem of ineffective writing in this section is normally found among the native English writers too. It depends on one's academic exposure to writing for international publication. Informant 1 , as an editor, shared the following experience:

People are always making suggestion for future research where if it has done in one context, we should do in another context. Why? Who care? I mean those suggestions for future research are pointless. They don't say anything important at all. And there are a lots of ideas like that but again there is always an issue of novice writers against experienced writers. I have got several native speakers. They are $\mathrm{PhD}$ students. They have the same problem.

Overall, there is no difference in terms of the awareness of rhetorical purposes of RA sections between the native English and Thai informants. Most informants agree that the level of authorial identity is best expressed in the discussion section. 


\section{Discussion}

In terms of linguistic disadvantage, this study found that the disadvantages of being a non-native English speaker still outweigh the advantages in terms of grammatical mistake, language clarity and coherence (lacking the logical connection or coherent set of ideas and arguments within a section or across sections). This problem in writing is similar to the findings by Jaroongkhongdacha, et al. (2012), who claim that Thai articles are of lower quality than international articles, especially in terms of justification, awareness and coherence. However, to some extent the present study discovers the existence of linguistic disadvantage among the Thai writers in international publication.

The experience in academia has been found to be the main factor which leads to a high quality academic writing for international publication. This view is also congruent with Hyland (2016) and Swales (2004) who argue that the distinction in publishing is not between the native English and non-native English writers but between experienced writers and less experienced ones. Hyland (2016) asserts that the native-non-native distinction is therefore a crude indicator of publishing success. In contrast to this view, Politzer-Ahles et al. (2016) argue that publishing may require less effort for native English speakers and may be biased in favor of native-like English. This study has also found the academic experience to be the main factor.

All of the native English informants felt comfortable to reveal themselves openly or assert themselves in their RAs explicitly as long as it remained appropriate. However, the Thai informants expressed their lack of confidence to assert themselves openly due to their concerns about getting negative feedbacks. This is in agreement with some previous studies (Flowerdew, 2001, Swales, 1990) which found that the Thai articles failed to provide an authorial comment which, according to Gosden's work, resulted in manuscript rejection (as cited in Jaroongkhongdacha, et al., 2012). According to Flick's work, without authorial voice, the Thai writers might simply list the previous literature without reflecting on and criticizing them (as cited in Jaroongkhongdacha, et al., 2012). In the present study, some of the informants attribute this conventional writing style to the Thai culture which promotes face saving and the need to be respected. This line of thought is also supported by Jaroongkhongdacha, et al. (2012), Kanoksilapatham (2007) and Pupipat (1998) who commented that for Thais, criticizing others' works, especially the works of writers of higher status, could be considered as face threatening, and thus should be avoided. Certain Thai cultural traits could then have impeded the ability to think critically and write argumentatively, conventionally essential skills of effective scientific writing (Pupipat, 1998). To sum up, how to balance authorial identity is an integral part of writing a research article for academic writers, regardless of whether they are native or non-native English writers.

In general, all the eight informants are aware of authorial identity through rhetorical purpose or function of RAs. Most of the informants agree that the level of authorial identity is best expressed in the discussion section (in line with Martin-Martin, 2008; Yang, 2013). However, the problem of the lack of proper use of hedging and analytical skill, especially in the introduction section and discussion section are dominant features in the academic writing of Thai writers (in line with Sukhanindr, 2008; Pupipat, 1998). In the same vein, Jaroongkhongdacha, et al. (2012) found that Thai articles are of lower quality than international articles, especially in the literature review and the discussion sections. Shaw (1991) suggests that the successful writing of the discussion section depends on appropriate employment of linguistic features as well as knowledge of linguistics and discourse. This problem may be attributable to the academic writing teaching in Thailand which tends to focus on form, rather than content. Sukhanindr (2008) suggests that the problematic use of hedges (i.e., using limited range of hedging devices and not understanding the meaning and the precise degree of certainty of modal verbs) is certainly relevant to academic writing instruction for Thai learners.

\section{Conclusion}

This study found the existence of linguistic disadvantage among Thai writers which suggest that non-native writers need to be abided by international standard in order to get their RAs published at international level. The knowledge about how to balance authorial identity is particularly crucial in teaching academic writing to non-native English learners especially the Thai learners because they may integrate cultural-specific and even personal elements into their writing. Thai teachers therefore need to train their students to show or express authorial identity or guide them into how to balance authorial identity to meet the expectations of the international academic community. Hyland (2004) proposes the use of hedges and boosters to show the writers' degree of confidence in the truth of a proposition and expressing an attitude to the audience. Therefore, academic writing course should emphasize more on the effective use of linguistic resources of authorial identity through rhetorical sections, especially the introduction and discussion sections, which is considered among the major problems found in non-native writers' work. A mix-method research approach is recommended for further research into this topic on linguistic disadvantage or authorial identity.

\section{References}

Al Fadda, H. (2012). Difficulties in academic writing: From the perspective of King Saud University Postgraduate Students. English Language Teaching Journal, 5(3), 123-130.

Braun, V. \& Clarke, V. (2013). Successful qualitative research: A practical guide for beginners. London: Sage.

Cadman, K. (1997). Thesis writing for international students: a question of identity?, English for Specific Purposes, 16, 3-14.

Chalapati, S. (2007).The internationalization of higher education in Thailand: Case studies of two English-medium business graduate programs. (Unpublished doctoral dissertation), RMIT University, Melbourne. 
Curry, M. J., and Lillis, T. M. (2010). Academic research networks: Accessing resources for English-medium publishing. English for Specific Purposes, 29, 281-295.

Flowerdew, J. (1999). Problems in writing for scholarly publication in English: The case of Hong Kong. Journal of Second Language Writing, 8(3), 243-264.

Flowerdew, J. (2001). Attitudes of journal editors to nonnative speaker contributions. TESOL Quarterly, 35, $121-150$.

Flowerdew, J. \& Wang, S. H. (2015). Identity in Academic Discourse. Annual Review of Applied Linguistics, 35, 8199.

Fox, H. (1994). Listening to the world; Cultural issues in academic writing. Urbana: National Council of Teachers of English.

Hyland, K. (2001). Humble servants of the discipline? Self-mention in research articles.

English for Specific Purposes, 20, 207-226. http://dx.doi.org/10.1016/S0889-4906(00)00012-0).

Hyland, K. (2002a). Options of identity in academic writing. ELT Journal, 56(4), 351-358

Hyland, K. (2002b). Authority and invisibility: Authorial identity in academic writing. Journal of Pragmatic, 34, 10911112.

Hyland, K. (2005). Stance and engagement: A model of interaction in academic discourse. Discourse Studies, 7(2), 173192.

Hyland, K. (2012). Disciplinary Identities: Individuality and Community in Academic Discourse. New York, NY: Cambridge University Press.

Hyland, K. (2016). Academic publishing and the myth of linguistic injustice. Journal of Second Language Writing, 31, 58-69

Hunston, S. \& Thompson, G. (2000). Evaluation: An introduction. In Hunston, S. and G. Thompson (Eds.). Evaluation in Text. Authorial Stance and the Construction of Discourse (pp. 1-27). Oxford: Oxford University Press.

Ivanic, R. (1998). Writing and identity; The discoursal construction of identity in academic writing. Amsterdam: John Benjamins Publishing Company.

Ivanic, R., \& Camps, D. (2001). I am how I sound: Voice as self-representation in L2 writing. Journal of Second Language Writing, 10, 3-33.

Jaroongkhongdach, W, Todd, R.W., Keyuravong, S., \& Hall, D. (2012). Differences in quality between Thai and international research articles in ELT. Journal of English for Academic Purposes, 11, 194-209.

Kamkhien, A. (2014). Linguistic features of evaluative stance: Finding from research article discussions. Indonesian Journal of Applied Linguistics, 4(1), 54-69

Kanoksilapatham, B. (2007). Writing scientific research articles in Thai and English: similarities and differences. Silpakorn University International Journal, 7, 172-203.

Kuhi, D., Tofigh, M. \& Babaie, R. (2013). Writers' self-representation in academic writing: the case of computer engineering research articles by English versus Iranian writers. International Journal of Research Studies in Language Learning, 2(3), 35-48.

Lin, M.H. (2013). A corpus-based approach to identity construction of L1 and L2 writers in academic discourse: An investigation of writers' self-representation in research articles in two disciplines. (Unpublished doctoral dissertation), University of Purdue, United States.

MaCrostie, J. (2008). Writer visibility in EFL learner academic writing: A corpus-based study. ICAME Journal, 32, 97114.

Martin-Martin, P. (2008). The mitigation of scientific claims in research papers: a comparative study. International Journal of English Studies, 8 (2), 133-152.

Okamura, A. (2006). How do Japanese researchers cope with language difficulties and succeed in scientific discourse in English. The Economic Journal of Takasaki City University of Economics, 48(3), 61-78

Pérez-Llantada, C. (2007). Native and non-native English scholars publishing research. Journal of Applied Linguistics, 4 (2): 217-238.

Petch-Tyson, Stephanie. (1998). Writer/reader visibility in EFL written discourse. In S. Granger, (Ed.). Learner English on Computer (pp.107-118). New York, NY: Longman.

Politzer-Ahles, S., Holliday, J., Girolamo, T., Spychalska, M. \& Berkson, K.H. (2016). Is Linguistic injustice a myth? A response to Hyland (2016), Journal of Second Language Writing, 34, 3-8.

Prince, A. (2000). Writing through cultures: The thesis writing experiences of five postgraduate research students from non-English speaking backgrounds and cultures, (MA Thesis), Department of Linguistics and Applied Linguistics, University of Melbourne. 
Pupipat, A. (1998). Scientific writing and publishing in English in Thailand: The perceptions of Thai scientists and editors. (Unpublished doctoral dissertation), Teachers College, Columbia University.

Scott M (1996). Wordsmith tools. Oxford: Oxford University Press.

Shaw, P. (1991). Genre Analysis. Cambridge: Cambridge University Press

Sukhanindr, M. (2008). Hedging in research articles about English language teaching written by Thai and native speakers of English. (MA Thesis). Department of Foreign Language. Kasetsart University. Bangkok. Thailand.

Swales, J. M. (1990). Genre analysis: English in academic and research settings. Cambridge: Cambridge University Press.

Swales, J. M. (2004). Research genres. Cambridge: Cambridge University Press.

Yang, Y. (2013). Exploring linguistic and cultural variations in the use of hedges in English and Chinese scientific discourse. Journal of Pragmatics, 50, 23-36. 